\title{
ERRATUM
}

In the November issue, Volume 17, No. 11, pages 1605-1615, in the article "Use of a Double Resonance Electron Capture Dissociation Experiment to Probe Fragment Intermediate Lifetimes" by Cheng Lin, Jason J. Cournoyer and Peter B. O'Connor, the order of the author names was inadvertently changed to conform to the journal style. The correct order of the authors is shown below. The publisher apologizes for the error.

\section{Cheng Lin}

Mass Spectrometry Resource, Department of Biochemistry, Boston University School of Medicine, Boston, Massachusetts, USA

\section{Jason J. Cournoyer}

Department of Chemistry, Boston University, Boston, Massachusetts, USA

\section{Peter B. O'Connor}

Mass Spectrometry Resource, Department of Biochemistry, Boston University School of Medicine, Boston, Massachusetts, USA 